\title{
Anaesthetic management of a pregnant woman with Chiari Malformation type 1 following failed endotracheal intubation for caesarean section
}

\author{
M. Henriksson, S. Harrison, Y. Rajakulendran, Dr D Dabrowska \\ West Middlesex University Hospital, London, United Kingdom
}

\section{BACKGROUND}

Chiari Malformation type $1(\mathrm{CM}-1)$ is a congenital anomaly where the hindbrain herniates into the foramen magnum and is associated with syringomyelia in $25 \%$ of cases. Consensus regarding the mode of delivery and anaesthetic management in parturients with $\mathrm{CM}-1$ remains controversial with regards to the risk of raised intracranial pressure (ICP) ${ }^{1}$.

We describe a patient with severe CM-1 and associated syringomyelia who had elective caesarean section (CS) under general anaesthesia (GA). Her airway was managed with a supraglottic device (iGel) after endotracheal intubation failed. To our knowledge this is the first report describing use of iGel in a patient with CM-1 during an elective CS.

\section{THE CASE}

32yo female, referred to the anaesthetic preoperative assessment clinic at 13/40 gestation in view of her CM-1 with associated syringomyelia and high body mass index (BMI).

\section{Past Medical History}

1. Severe CM-1 (cerebellar tonsillar herniation of $12 \mathrm{~mm}$ ) and extensive cervicothoracic syrinx (extending from C2 to T5)

- Due to have foramen magnum decompression when found out that she was pregnant on preoperative urine pregnancy test $\rightarrow$ operation postponed until after delivery - Symptoms: Headache, unsteady gait, neck and right upper limb pain with associated paraesthesia

2. BMI $40(103 \mathrm{~kg}, 158 \mathrm{~cm})$

3. Gestational diabetes (insulin dependent)

\section{Multidisciplinary Team Discussion:}

\section{* Obstetric plan:}

Accelerated fetal growth $>97$ th centile

Vaginal delivery too high risk $\rightarrow$ plan for elective CS

* Neurosurgical and neuroanaesthetic advice:

Headache + unsteady gait secondary to cerebellar tonsillar herniation + symptomatic extensive syrinx Strongly advised against neuroaxial anaesthesia Recommend GA with neuroprotective measures

\section{ON THE DAY OF THE ELECTIVE CAESAREAN SECTION}

Two senior anaesthetic consultants present, agreed airway plan:

Asleep intubation with opioids, fibreoptic/glidoscope ready

In case of failed intubation: iGel as rescue plan $\rightarrow$ if good oxygenation acheived; to continue with CS on iGel

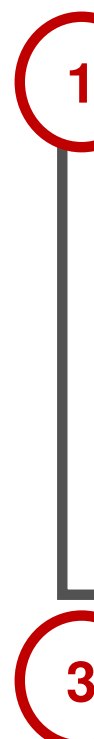

11:25am - Prior to induction: Oxford pillow

Sodium citrate

$2 \times 16 \mathrm{G}$ cannulae

Awake arterial line Optiflow 30L

Equipment available: McCoy, Glidoscope, Fibreoptic

\section{Airway Assessment:}

- Mallampati 4

- Thyromental distance $<6 \mathrm{~cm}$

- Jaw protrusion grade $A$

- Limited c-spine flexion/extension

- Small mouth

- No previous intubation attempts

\section{* Anaesthetic plan:}

Not for spinal or epidural anaesthesia Elective CS under GA with neuroprotective measures Plan for difficult airway Awake versus asleep intubation $\rightarrow$ up to anaesthetic consultant on the day

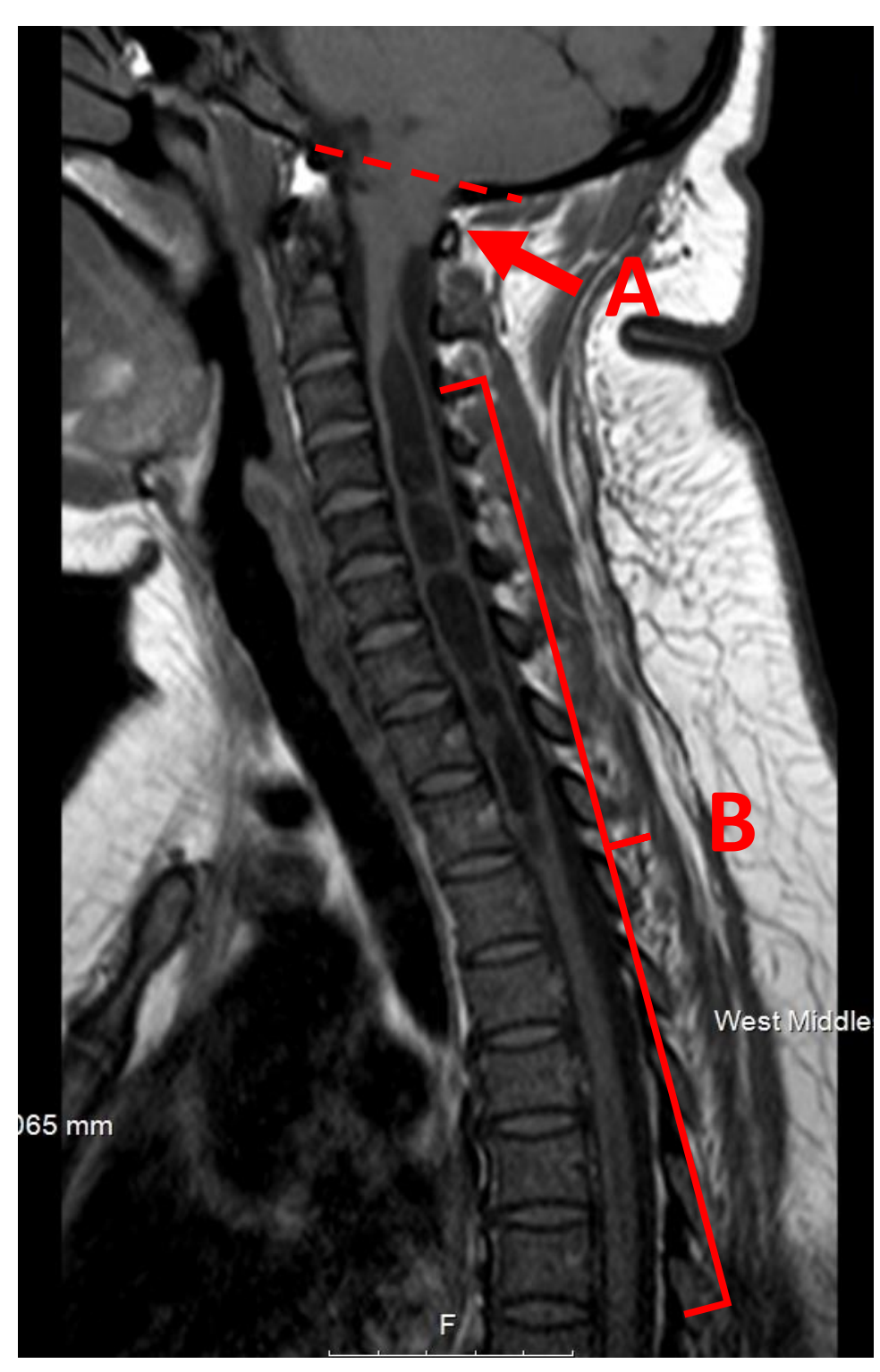

Magnetic resonance image of our case demonstrating: A) cerebellar tonsillar descent below the dotted line, B) extensive multi-septated syrinx extending from $\mathrm{C} 2$ to $\mathrm{T} 5$.

\section{DISCUSSION}

1. MDT discussion is paramount, clinical decision on an individual basis Previous case reports of successful neuroaxial anaesthesia in CM-1 parturients without worsening of neurological condition ${ }^{2}$

Our case was deemed too high risk if accidental dural puncture

2. Airway plan and management

Asleep intubation with opioid cover and tight control of blood pressure Due to grade 4 view, bleeding and drop in oxygen saturation iGel was inserted as per rescue plan, oxygen saturation maintained $>95 \%$ Hypercarbia with pCO2 $6.5 \mathrm{kPa}$

3. Previous case reports of airway difficulties in $\mathrm{CM}-1$ parturients Known difficult airway $\rightarrow$ awake fibreoptic ${ }^{1}$

Successful intubation 2nd attempt using laryngoscope airtraq ${ }^{3}$

\section{4. iGel supraglottic airway and caesarean section}

Supraglottic airway the most common rescue plan in failed intubation 4 Randomised study supporting the use of iGel in elective CS $^{5}$

\section{What could we have done differently?}

Pre-operative ENT nasendoscopy to assess for intubation Awake fibreoptic intubation / use of glidoscope at start Wake patient up if failed intubation $\rightarrow$ however, obstetric concern re: baby's size and elective CS already moved forward by one week

Bilateral transversus

Bilateral transversus abdominis plane block Sugammadex $200 \mathrm{mg}$ Labetalol on emergence Optiflow 30L

Nil new neurological deficit Morphine PCA

Monitored on HDU for 24 hours

Discharged home day 2 post-operatively

\section{CONCLUSION}

We have shown that it is possible to use an iGel airway after failed intubation in a parturient with severe $\mathrm{CM}-1$ for CS with a good outcome and no neurological deterioration.

However, due to the difficulty in controlling the pCO2 and thereby the risk of increasing the ICP, we would only recommend iGel use in $\mathrm{CM}-1$ parturients for emergency airway rescue.
9 at 1 and 5 minutes, cord gas $\mathrm{pH} 7.23$ pCO2 6.5kPa, pO2 15.3kPa, Lac 1.5

\section{References:}

1. Ghaly et al., Management of Parturients in active labour with Arnold Chiari malformation, tonsillar herniation and syringomyelia. Surg Neurol Int. 2017 8: 1-10

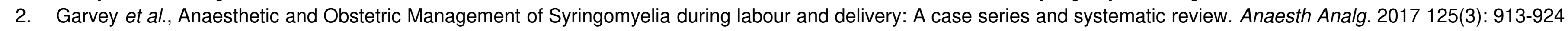

3. Mustapha et al., Difficult intubation in a parturient with syringomyelia and Arnold-Chiari malformation: use of airtraq laryngoscope. Saudi $J$ Anaesth 20115 : $419-22$

4. Quinn et al., Failed tracheal intubation in obstetric anaesthesia: 2 yr national case-control study in the UK British Journal of Anaesthesia 2013 110(1): 74-80

5. Farhat et al., I-gel versus cuffed endotracheal tube in elective caesarean section (double-blind randomized study) Ain-Shams Journal of Anesthesiology 2015 8:511-515 